\title{
Solid Pseudopapillary Neoplasm of the Pancreas
}

National Cancer Institute

\section{Source}

National Cancer Institute. Solid Pseudopapillary Neoplasm of the Pancreas. NCI

Thesaurus. Code 137212.

\begin{abstract}
A low-grade malignant neoplasm that arises from the exocrine pancreas. It is characterized by the presence of uniform cells that form solid and pseudopapillary patterns, cystic changes, and hemorrhage. Perineural invasion, vascular invasion, and invasion into surrounding tissues may be present. It usually presents as an encapsulated, solitary, and lobulated pancreatic mass. It is usually found incidentally during physical examination or it may present with abdominal discomfort and pain. It occurs predominantly in young women. Complete removal of the tumor is curative in the majority of cases.
\end{abstract}

